\title{
Development of New PM Iron-Based Materials for Self-Lubricating Bearings
}

\author{
Cristina Teisanu and Stefan Gheorghe \\ Faculty of Mechanics, University of Craiova, 107 Calea Bucuresti, 200512 Craiova, Romania \\ Correspondence should be addressed to Cristina Teisanu, cteisanu@yahoo.com
}

Received 30 June 2011; Revised 22 September 2011; Accepted 27 September 2011

Academic Editor: Pedro Arrazola

Copyright ( $) 2011$ C. Teisanu and S. Gheorghe. This is an open access article distributed under the Creative Commons Attribution License, which permits unrestricted use, distribution, and reproduction in any medium, provided the original work is properly cited.

Using PM technologies, new antifriction materials based on iron powder with different addition elements were developed in order to obtain self-lubricated bearings with improved tribological features. The elemental powder mixtures were blended for 2 hours in a $3 \mathrm{D}$ homogenization device, were compacted at a pressure of $500 \mathrm{MPa}$, and then sintered in dry hydrogen atmosphere at different temperatures for different maintaining times. The effect of technological parameters on physical properties (density and dimensional changes) was presented in this study. The mechanical and tribological properties (tensile strength, hardness, impact energy, friction coefficient, and wear rate) related to addition elements were evaluated. The tribological behaviour of the selected iron-based alloys was analysed by pin on disc tests without lubrication. Also, the wear surface scars and the microstructure of the wear surfaces were investigated.

\section{Introduction}

Self-lubricating bearings represent the oldest industrial application of the porous materials obtained by PM technique as metallic filters and sparking plugs cannot be produced by other technology. In the recent years iron-based sintered bearings production was considerably increased at the expense of the copper-based ones, due to the low cost and availability of the iron powders as well as their higher strength. The mechanical properties of the parts are strongly related to the composition of the material. For tribological applications, the properties of the surface are linked to the different metallic and intermetallic phases formed in the material.

Controlled inhomogeneity of the structure by powder metallurgy processes makes it possible to obtain materials with special properties, which cannot be manufactured by conventional technologies. Many sintered parts reach sufficiently high-strength properties, for example, similar to cast iron, already at a porosity of $20-15 \%$. The great advantage of the porous materials over the compacted ones obtained by conventional technologies is their porosity, which acts like its own oil reservoir. Self-lubricating bearings accomplish superior performance when the porosity level is high, so sufficient oil is accumulated in the pores during inactivity periods and it leaks when the shaft begins rotating in it. Also, the material density plays an important role for self-lubricating bearings for exhibiting good load-bearing capacity. Therefore, it is essential to know the actual loading conditions of the part and modify the alloying and the treatment conditions of the material on the basis of these conditions.

Sintered iron-based antifriction materials were not developed until the last decades because of their poor corrosion resistance and antifriction properties. Considering the low cost and availability of iron, additions such as copper, graphite, manganese, lead, phosphorous, boron, and tin to iron have been attempted, but improvement in one property was offset by a decrease in other properties [1-4]. In order to enhance antifriction and mechanical properties, the present paper focuses on the development of $\mathrm{Fe}-\mathrm{Cu}-\mathrm{Sn}-\mathrm{Pb}-\mathrm{MoS}_{2}$ antifriction alloys.

As the quality of the material powders and the manufacturing processes were improved, powder metallurgy parts had in many cases taken the place of cast and forged products. It is very important, in order to avoid subsequent operations such as sizing and machining, to improve the final dimensional tolerances obtained after sintering. There are 
TABLE 1: Composition of the powder mixtures.

\begin{tabular}{lccccc}
\hline Alloy & $\begin{array}{c}\text { Iron } \\
\mathrm{wt} \%\end{array}$ & $\begin{array}{c}\text { Copper } \\
\mathrm{wt} \%\end{array}$ & $\begin{array}{c}\text { Tin } \\
\mathrm{wt} \%\end{array}$ & $\begin{array}{c}\text { Lead } \\
\mathrm{wt} \%\end{array}$ & $\begin{array}{c}\mathrm{MoS}_{2} \\
\mathrm{wt} \%\end{array}$ \\
\hline 1 & Rest & 5 & 1 & 7.5 & 1 \\
2 & Rest & 5 & 1.5 & 5 & 1 \\
3 & Rest & 5 & 2.5 & 2.5 & 1 \\
\hline
\end{tabular}

TABle 2: Experimental conditions.

\begin{tabular}{llc}
\hline Sintering conditions & $\begin{array}{l}\text { Sintering temperature }\left[{ }^{\circ} \mathrm{C}\right] \\
\text { Holding time [min.] } \\
\text { Atmosphere }\end{array}$ & $\begin{array}{c}800-900 \\
20,35,50 \\
\text { Dry hydrogen }\end{array}$ \\
\hline Sintered density $\left[\mathrm{g} / \mathrm{cm}^{3}\right]$ & $6.5-6.9$ \\
\hline
\end{tabular}

TABLE 3: Density values of the sintered mixtures.

\begin{tabular}{|c|c|c|c|c|}
\hline \multirow{2}{*}{ Sintering temperature } & \multirow{2}{*}{ Dwell time } & \multicolumn{3}{|c|}{ Density } \\
\hline & & Alloy 1 & Alloy 2 & Alloy 3 \\
\hline \multirow{3}{*}{800} & 20 & 6.81 & 6.68 & 6.59 \\
\hline & 35 & 6.87 & 6.72 & 6.54 \\
\hline & 50 & 6.85 & 6.8 & 6.71 \\
\hline \multirow{3}{*}{850} & 20 & 6.79 & 6.58 & 6.56 \\
\hline & 35 & 6.84 & 6.61 & 6.55 \\
\hline & 50 & 6.83 & 6.67 & 6.57 \\
\hline \multirow{3}{*}{900} & 20 & 6.72 & 6.54 & 6.54 \\
\hline & 35 & 6.76 & 6.53 & 6.52 \\
\hline & 50 & 6.73 & 6.54 & 6.53 \\
\hline
\end{tabular}

many factors that cause dimensional changes, and their combined effect makes it more difficult to forecast and control these changes. In the present paper, the experimental results of influence the different parameters on the dimensional changes of the sintered iron based alloys was reported.

Also, the density of the sintered parts was investigated and, thus, the effect of the sintering temperature and time on the density of the iron-based materials for self-lubricating bearings was studied.

These influences of the sintering parameters on the density and dimensional changes are presented as $3 \mathrm{D}$ surface plots using Statistica software.

\section{Materials and Experimental Procedure}

As experimental materials, iron powder produced by DUCTIL S.A. BUZAU (DP 200-HD), electrolytic copper powder, tin powder, lead powder, and molybdenum disulphide powder were used. Because of its lamellar structure, $\mathrm{MoS}_{2}$ is one of the most popular and usable solid lubricants. $\mathrm{MoS}_{2}$ is used to reduce the interparticle friction as well as friction between powder particles and die wall during conventional cold die compaction. Lead exhibits excellent self lubricating property and plays a role of solid lubricant to prevent seizure. In addition, since $\mathrm{Pb}$ forms a soft dispersion phase, it has conformability and allows solid matter to be embedded therein. Tin is a key player in antifriction alloys because it can influence both corrosion resistance and fatigue strength and friction and wear properties of these materials can also be improved.

Elemental powders were weighed to the selected proportions and mixed for 2 hours in 3D homogenization device. Then, test pieces were cold compacted at $500 \mathrm{MPa}$ into a rigid die by applying pressure in a single axial direction through a rigid punch or piston, and cylindrical specimens with $10 \mathrm{~mm}$ diameter and $7 \mathrm{~mm}$ height were obtained and used for metallographic examination and measurement of green and sintered density, porosity, and dimensional change after sintering.

Green samples were placed in a tubular furnace having a uniform heating zone and sintered at 800,850 , and $900^{\circ} \mathrm{C}$ for 20,35 , and 50 minutes. The sintering atmosphere was dry hydrogen with a flow rate of $1 \mathrm{~L} / \mathrm{min}$. Samples were then furnace-cooled by switching off the power and maintaining the same flow rate of the hydrogen gas.

Reference densities for the selected compositions were calculated by the rule of mixtures, and sintered densities were evaluated gravimetrically using the Archimedes principle. Volumetric dimensional change of the sintered compacts was calculated, and the total porosity of the specimens was evaluated from the difference between the reference density and the measured density.

Experimental conditions and the composition of the powder mixtures are presented in Tables 1 and 2, and densities of the sintered compacts are shown in Table 3.

Specially shaped specimens were produced by PM technology for testing the tensile strength of the PM parts in conformity with operating standardization.

Hardness test for PM materials was carried out using the Vickers method with an indentation load of $50 \mathrm{~N}$.

Impact energy was determined by the Charpy test according to SR EN 10045-1-93 using $5 \times 10 \times 55 \mathrm{~mm}$ specimens without notches.

Tribological behaviour of the sintered samples was analysed under dry friction conditions by pin-on-disc test using a testing device for friction coefficient and wear rate measurements (Figure 1) at a sliding speed of $0.75 \mathrm{~m} / \mathrm{s}$ and a specific load of $3.72 \mathrm{MPa}$ giving $p \times v$ value of $2.8 \mathrm{MPa} \mathrm{m} / \mathrm{s}$. Loadcarrying ability is an important tribological behaviour of a dry sliding couple. The $p v$ factor or $p \times v$ value characterizes the mechanical input in a sliding bearing as severity of design or the maximum mechanical input that the tribomaterials can support [5]. Cylindrical specimens of $10.5 \mathrm{~mm}$ diameter and $7 \mathrm{~mm}$ height were used for wear tests. The mating part was made from 1C45 (SR EN 10083-1,2) with 235 HB.

The friction coefficient was calculated using relation (1), along the sliding distance of $1360 \mathrm{~m}$ :

$$
\mu=\frac{F_{f}}{F},
$$

$F_{f}$ is the friction force and $F$ is the resulting force acting on the lever.

The wear rate was performed for materials sintered at $900^{\circ} \mathrm{C}$ for 50 minutes because of their better values of the mechanical and physical characteristics compared with those sintered at $850^{\circ} \mathrm{C}$ and $800^{\circ} \mathrm{C}$. The wear rate was evaluated at $p \times v=2.8 \mathrm{MPam} / \mathrm{s}$ and calculated in terms of the worn 

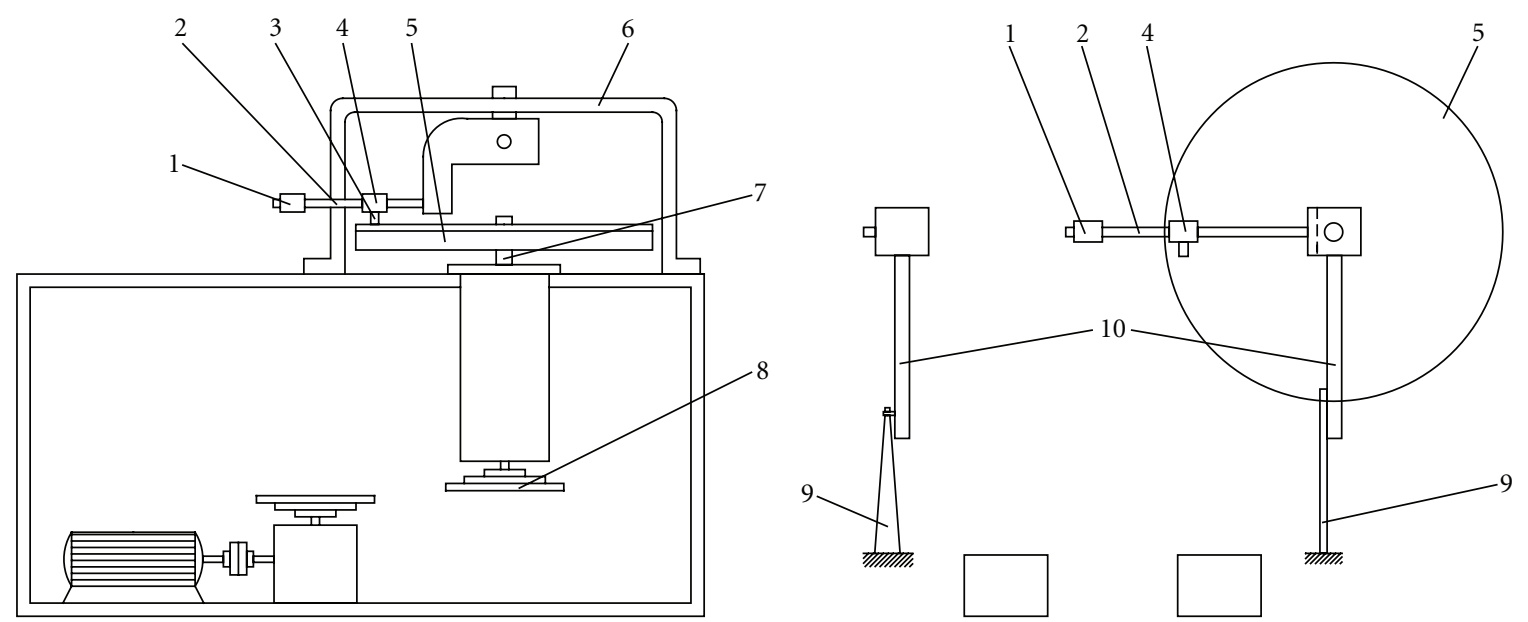

Figure 1: Testing device for friction coefficient and wear rate measurements: 1: weight; 2: ruler; 3: pin sample; 4: pin sample blocking part; 5: mating disc; 6: rigid frame; 7: driving shaft; 8: trapezoidal transmission; 9: elastic lamella; 10: lever.

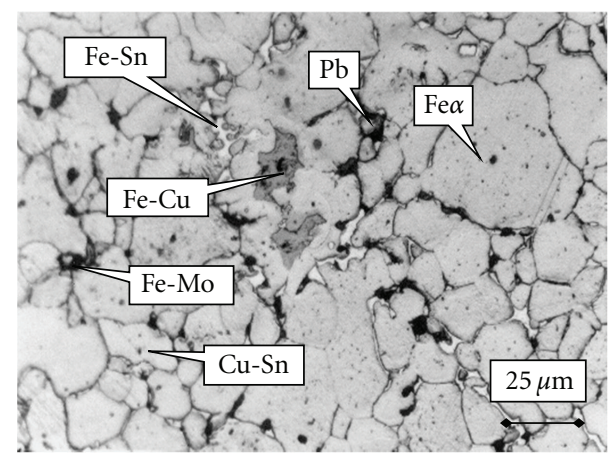

(a)

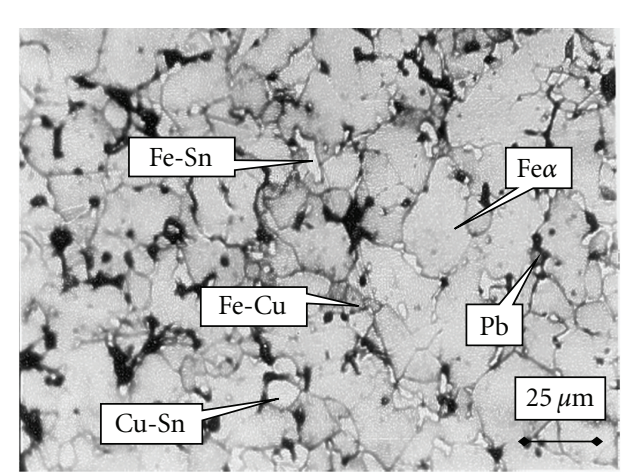

(b)

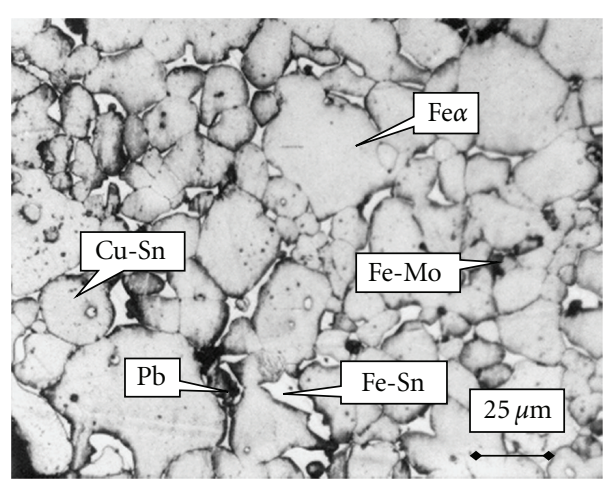

(c)

Figure 2: Microstructure of the alloys 1 (a), 2 (b), and 3 (c) sintered at $900^{\circ} \mathrm{C}$ for 50 minutes.

layer thickness of the sample per sliding distance and in terms of the worn volume of the tested sample per sliding distance using reference density of each compact. Linear wear rate and volumetric wear rate were determined as follows: (2) $\Delta h$ is the thickness of the worn layer $(\mathrm{mm})$,

$$
I_{g}=\frac{\Delta V}{L_{\text {sliding }}}\left[\mathrm{mm}^{3} / \mathrm{m}\right],
$$

$\Delta V$ is the volume of the worn material $\left(\mathrm{mm}^{3}\right)$ and $L_{\text {sliding }}$ the sliding distance $(\mathrm{m})$.
The wear surface characteristics were emphasized by SEM images.

\section{Results and Discussions}

3.1. Microstructure and Physical Properties. Representative microstructures of the selected alloys are shown in Figure 2, and microscopic investigations of the specimens porosity are presented in Figure 3. 


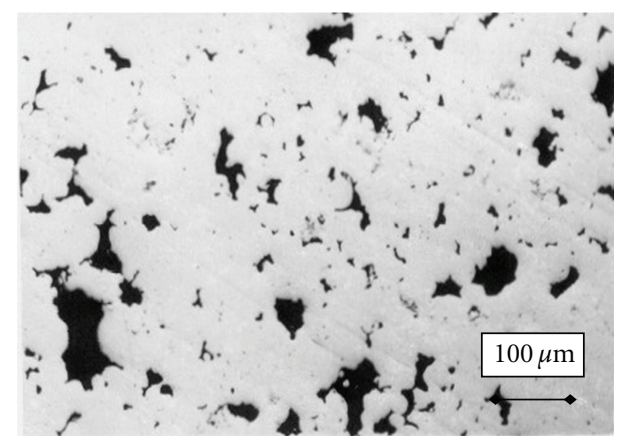

(a)

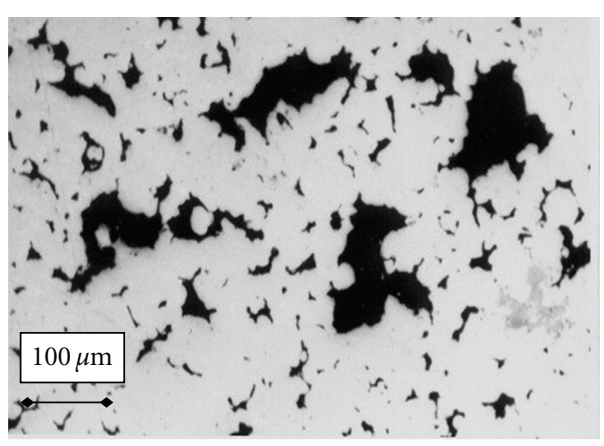

(b)

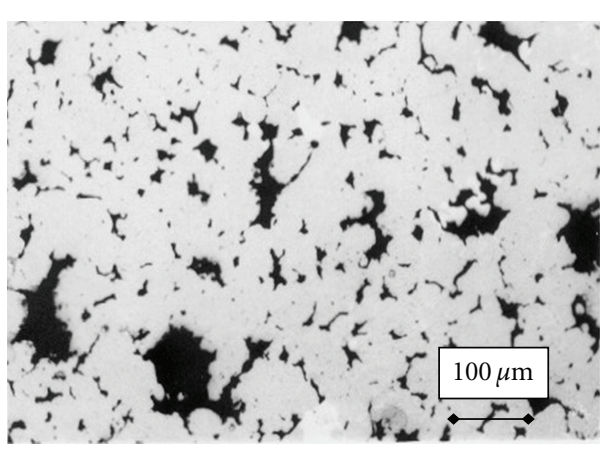

(c)

Figure 3: Porosity of the alloys 1 (a), 2 (b), and 3 (c) sintered at $900^{\circ} \mathrm{C}$ for 50 minutes.

These microstructures emphasize a relatively uniform distribution of the phases in the ferrite matrix, with distinctive boundaries. Few globular $\mathrm{Pb}$ grains and $\mathrm{Cu}-\mathrm{Sn}$ grains can be distinguished in all compositions, as well as elongated $\mathrm{Fe}-\mathrm{Sn}$ intermetallic compounds scattered in the Fe $\alpha$ matrix around ferrite grains. This arrangement of the grains is typical to the final stage of the liquid-phase sintering when liquid occupies the space between the grains. Also, some Fe-Mo grains can be seen in compositions with $1 \% \mathrm{Sn}$ and $2.5 \% \mathrm{Sn}$ and some $\mathrm{Fe}-\mathrm{Cu}$ grains in alloys 1 and 2 . There are few small pores in samples with $1 \% \mathrm{Sn}$ and $2.5 \% \mathrm{Sn}$, but the sample containing $1.5 \% \mathrm{Sn}$ exhibits a higher level of porosity with pores of irregular shape placed mainly at the grain boundaries.

Optical micrographs of the polished and unetched surfaces of the sintered compacts made from alloys 1,2, and 3 show different levels of porosity. There are few large pores in each sample with irregular shapes and sharp edges, except for some with rounded shape (Figure 3(a)), and with a nonuniform distribution into the metallic matrix in all samples. Small pores can be observed in larger quantities with a relatively more homogeneous distribution as the tin content increases, with acicular and spot-like shapes.

Certain physical features of the sintered materials have a major importance because of their influence on some mechanical properties (tensile strength, compression strength, toughness, and hardness), antifriction, and self-lubricating properties.

The density of the sintered samples made from the selected alloys $(1,2$, and 3$)$ as a function of sintering time and temperature was characterized.
The 3D graphic dependences of the density versus sintering temperature for the selected materials compacted at $500 \mathrm{MPa}$ and maintained in the heating zone for 20,35 , and 50 minutes are presented in Figures 4, 5, and 6.

From the analysis of the presented charts it can be observed a decrease of the sintered density as the temperature is getting higher for all three alloys. For samples containing $1 \% \mathrm{Sn}$ and sintered at all temperatures the density shows an increase as the sintering time reaches 35 minutes and then it decreases as the sintering time continues up to 50 minutes. A dissimilar trend is observed for samples with $2.5 \%$ Sn at all sintering temperatures with respect to maintaining time. For the alloy with $1.5 \%$ Sn sintered density presents an ascending variation when heating at $800^{\circ} \mathrm{C}$ and $850^{\circ} \mathrm{C}$ for 20,35 , and 50 minutes and a descending variation when sintering at $900^{\circ} \mathrm{C}$ for all three maintaining times. The smallest values of the sintered density are recorded for 20 minute sintering time for alloy no. 1 and for 35 minutes for alloys no. 2 and 3 .

This behaviour of the sintered density is attributed to the compact swelling during liquid-phase sintering. The formation of a copper-tin alloy at the neck of the iron-tin intermetallic compound generates the initial decrease of the densification by restricting diffusion of low melting phases into the network to fill the pores. Since the diffusion coefficient of copper in tin is higher than that of iron in tin at a temperature of about $850^{\circ} \mathrm{C}$, the formation of iron-tin intermetallics contributes to the increase in intercommunicating porosity, and thus a less densification. Increasing of the density occurs when soft phases diffuse into the pores. Pore filling by liquid preferentially starts at a localized region in the compact and spreads during liquid-phase sintering. Small pores fill first 


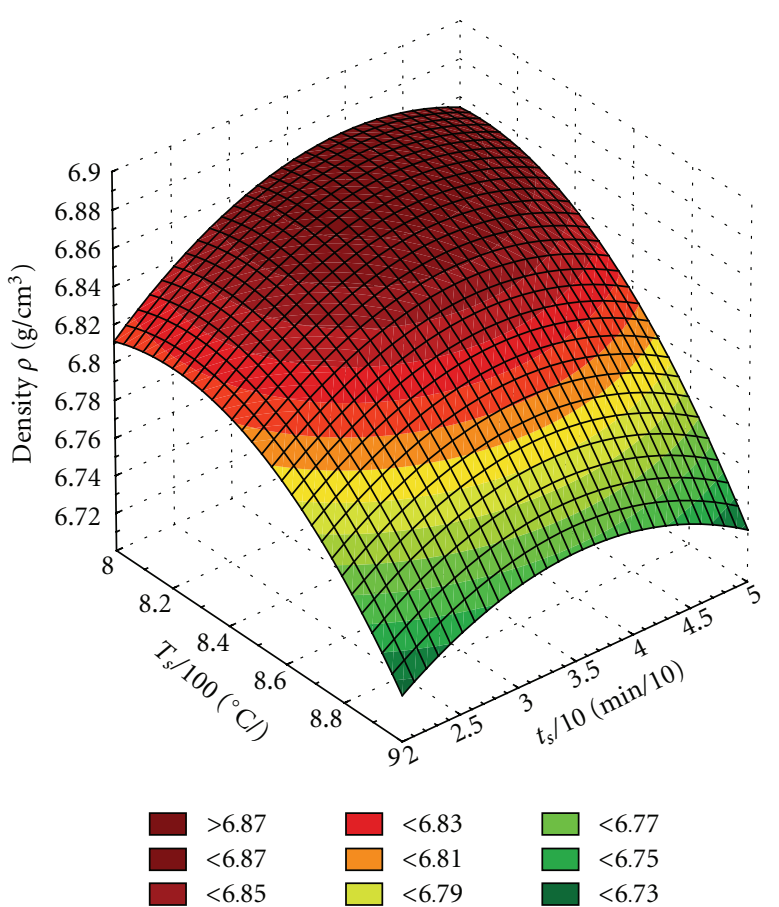

Figure 4: The dependence of the density: $\rho=f\left(T_{s}, t_{s}\right)$ is the alloy no. 1 .

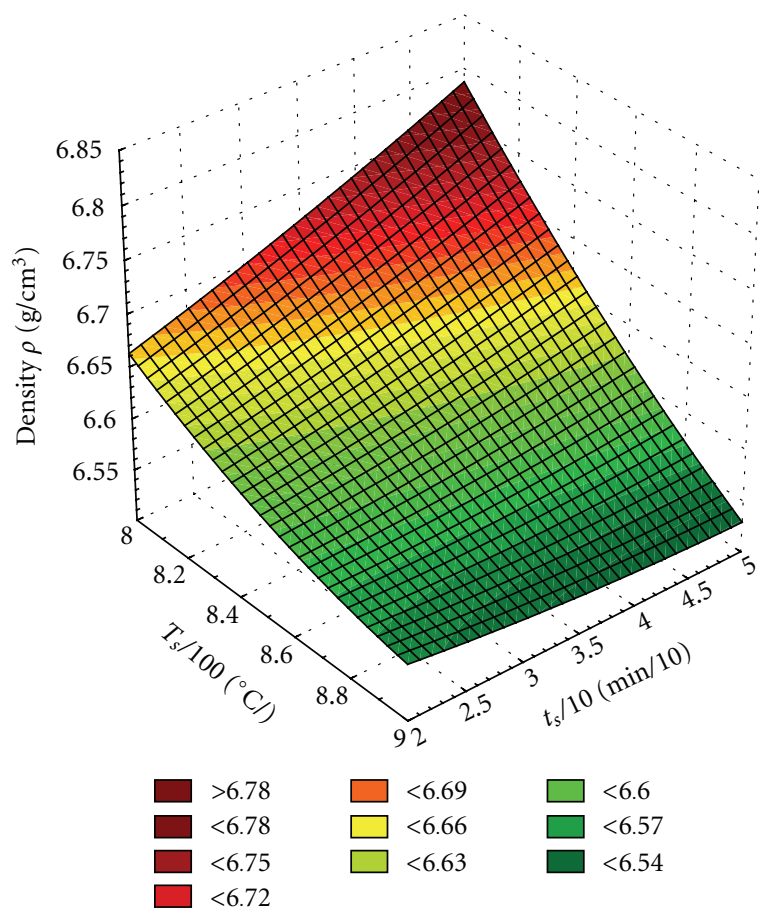

Figure 5: The dependence of the density: $\rho=f\left(T_{s}, t_{s}\right)$ is the alloy no. 2.

since they have the highest capillary attraction for the wetting liquid. High-green-density regions correspond to smaller pores, so pore filling naturally favours the high-green-density regions [6].

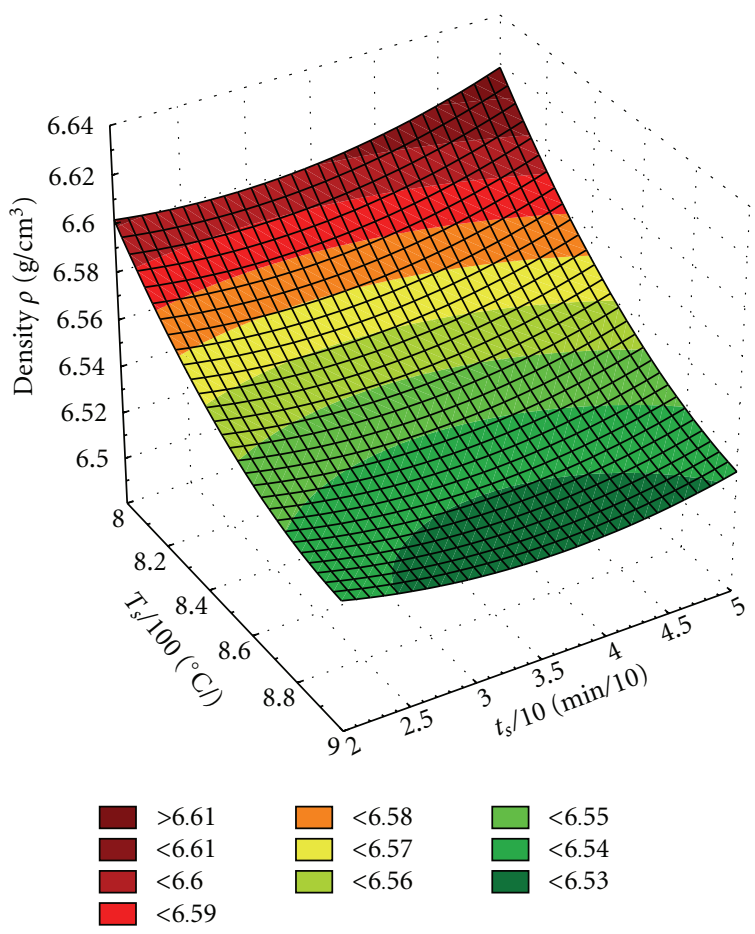

FIgure 6: The dependence of the density: $\rho=f\left(T_{s}, t_{s}\right)$ is the alloy no. 3 .

In Figures 7, 8, and 9 the dependence of the dimensional changes on sintering parameters (temperature and time) of the iron-based sintered samples is shown.

The large expansion of the dimensions observed for all alloys sintered at $900^{\circ} \mathrm{C}$ is possible due to liquid penetration of the grain boundaries which causes grain separation and swelling on liquid formation. This penetration action pushes more solid particles apart, increasing the distance between particle centres and consequently leading to the growth of the compacts [7]. This behaviour is attributed probably to the formation of $\mathrm{Cu}-\mathrm{Sn}, \mathrm{Fe}-\mathrm{Cu}$, and $\mathrm{Fe}-\mathrm{Sn}$ compounds in larger amounts at higher temperatures as the tin content increases. Liquid tin has substantial solubility in the solid iron; thus compact swelling due to pore formation at prior particle sites occurs.

Decreasing the dimensional changes is attributed to the formation of the Fe-Sn phase at higher temperatures, which has a lower coefficient of thermal expansion than iron. Another cause of the dimensional growth might be attributed to the trapped hydrogen in the pores as the sintering process was performed in hydrogen atmosphere.

3.2. Mechanical Properties. Tensile strength for shaped specimens sintered in the specified conditions is presented in Figure 10 as a function of the tin content.

The tensile strength has the higher values for all compositions sintered at $900^{\circ} \mathrm{C}$ and decreases with the decrease of the Sn content. The same tendency is observed for all sintering temperatures. This behaviour may be due possibly to the formation at higher temperatures of some strengthening phases like $\mathrm{Fe}-\mathrm{Cu}, \mathrm{Fe}-\mathrm{Sn}, \mathrm{Fe}-\mathrm{Mo}$, and $\mathrm{Cu}-\mathrm{Sn}$ and to the gradual 


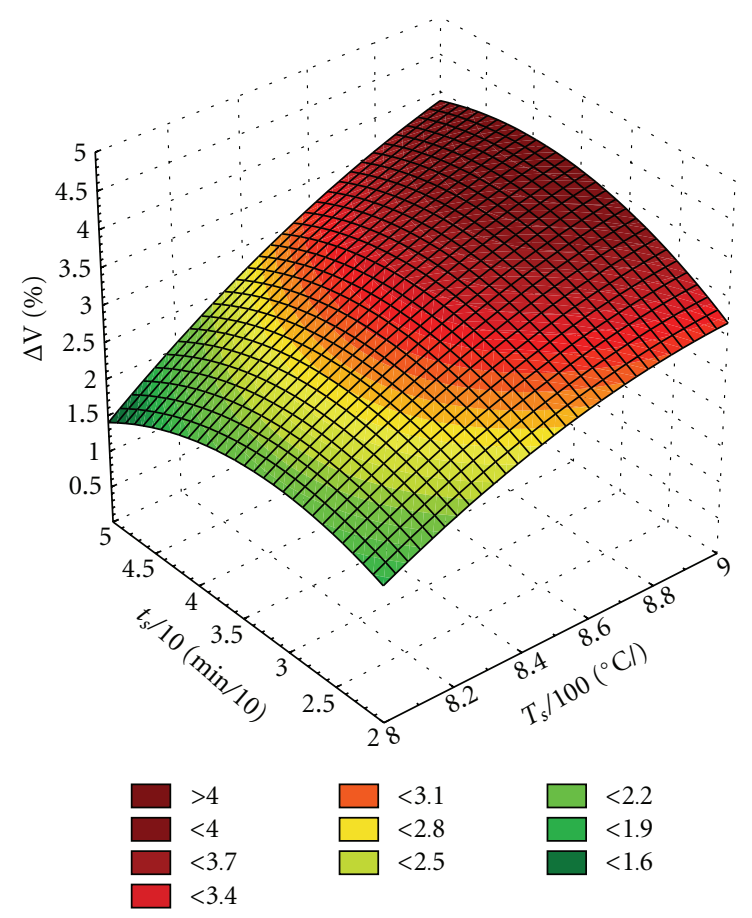

Figure 7: The effect of sintering parameters on dimensional changes for alloy no. 1 .

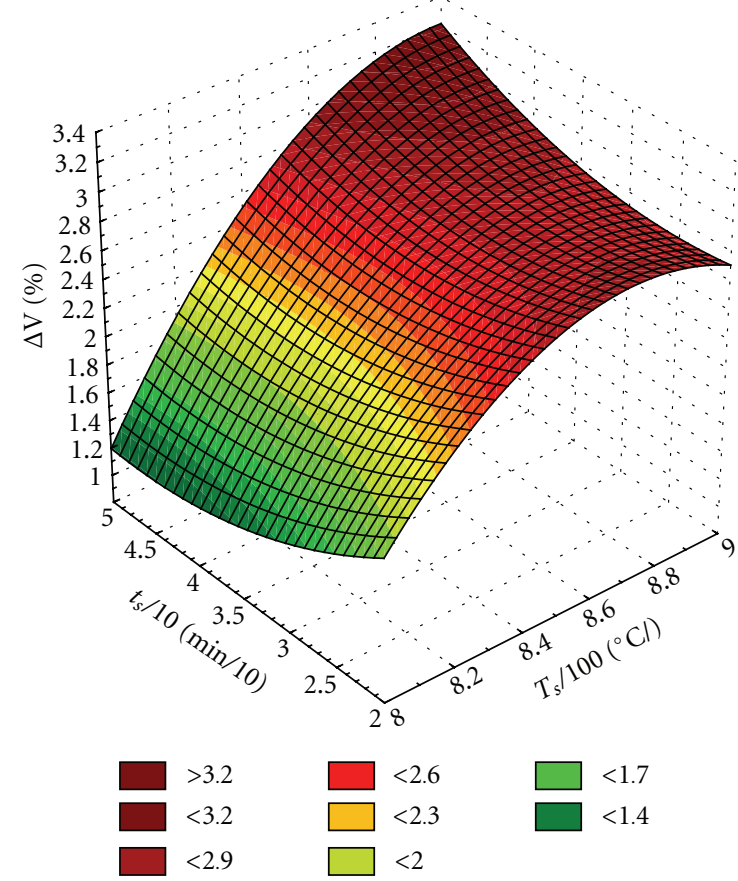

Figure 8: The effect of sintering parameters on dimensional changes for alloy no. 2 .

increase of the solid skeleton solubility in the transient liquid phase as the temperature is getting higher.

The influence of the chemical composition on the hardness and impact energy is depicted in Figures 11-13.

For all samples sintered at $900^{\circ} \mathrm{C}$ the highest values of the hardness were obtained. All the selected compositions have

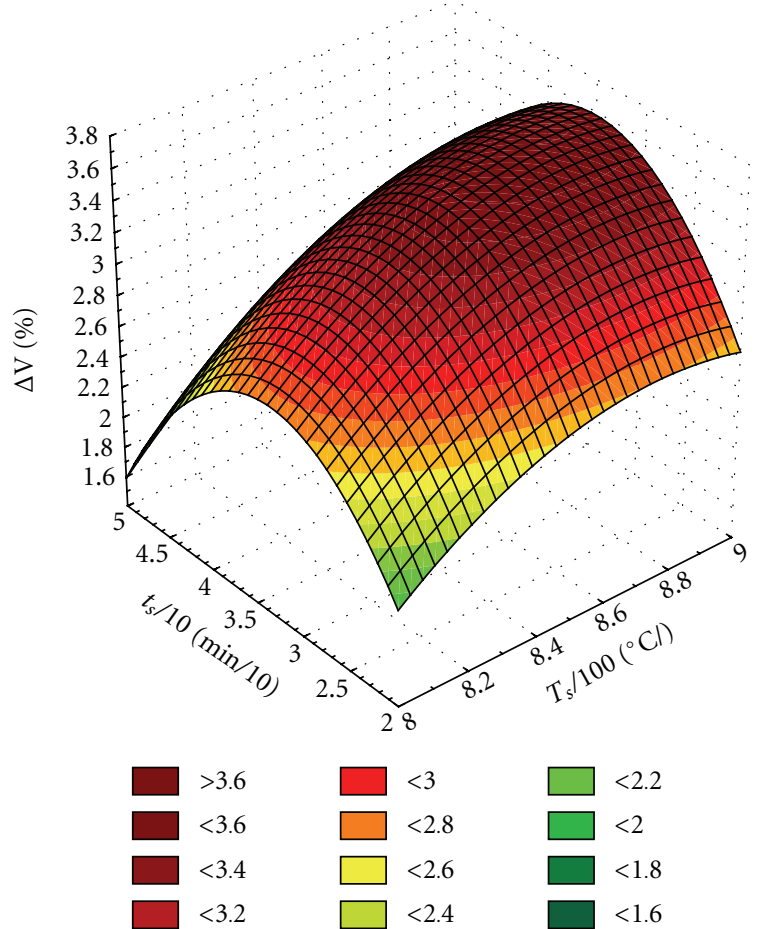

Figure 9: The effect of sintering parameters on dimensional changes for alloy no. 3 .

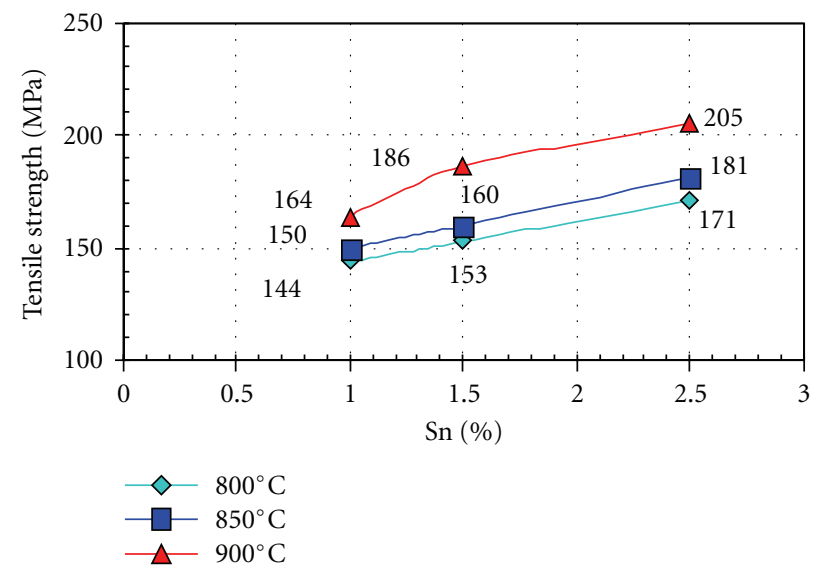

FIGURE 10: Influence of the Sn content on tensile strength.

almost the same hardness behaviour at all three sintering temperatures, except for the one containing $1.5 \% \mathrm{Sn}$ and sintered at $800^{\circ} \mathrm{C}$ which presents an increased value of the hardness. This can be explained by the presence of some strengthening phases such as $\mathrm{Fe}-\mathrm{Sn}, \mathrm{Fe}-\mathrm{Cu}$, and $\mathrm{Cu}-\mathrm{Sn}$ which form due to longer time available for diffusion processes. The highest value of the hardness $\left(139 \mathrm{VH}_{5}\right)$ was exhibited for the sample with $2.5 \% \mathrm{Sn}$ sintered at $900^{\circ} \mathrm{C}$.

The aim of the Charpy test is to establish the notch toughness of the material, defined as the work (impact energy) used to fracture the specimen under test conditions. The Charpy impact tests on unnotched samples were conducted with an instrumented pendulum at room temperature 


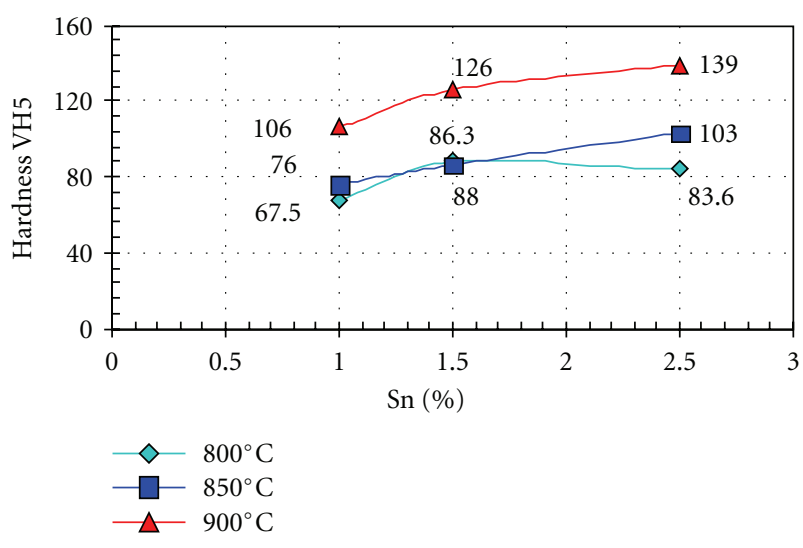

FIGURE 11: The effect of the Sn content on the Vickers hardness.

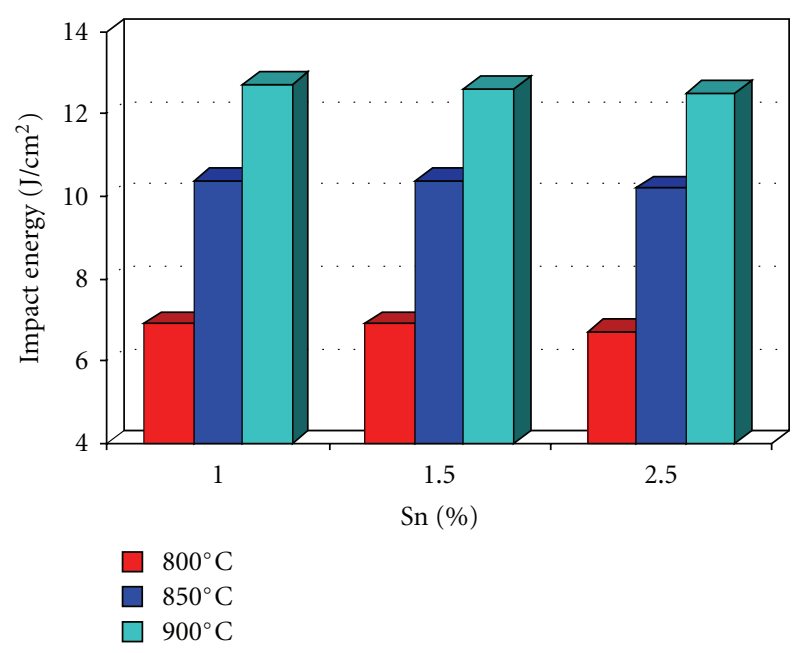

Figure 12: The effect of the Sn content on the impact energy.

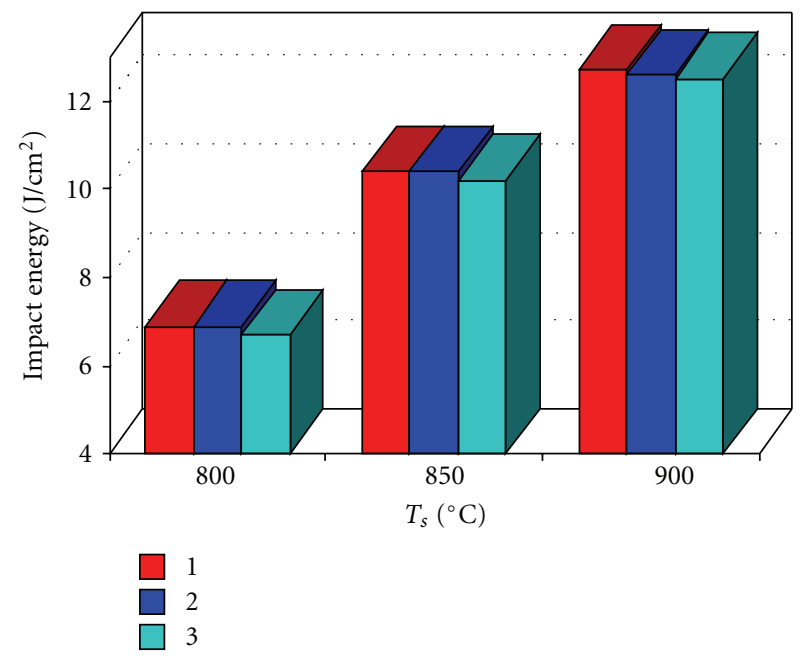

FIGURE 13: The effect of the sintering temperature on the impact energy.
TABle 4: The Charpy test results.

\begin{tabular}{ccccccc}
\hline \multicolumn{6}{c}{ Alloy } & \multicolumn{5}{c}{ Sintering temperature $\left[{ }^{\circ} \mathrm{C}\right]$} \\
& & 800 & 850 & 900 \\
& $E[\mathrm{~J}]$ & $\mathrm{KC}\left[\mathrm{J} / \mathrm{cm}^{2}\right]$ & $E[\mathrm{~J}]$ & $\mathrm{KC}\left[\mathrm{J} / \mathrm{cm}^{2}\right]$ & $E[\mathrm{~J}]$ & $\mathrm{KC}\left[\mathrm{J} / \mathrm{cm}^{2}\right]$ \\
\hline 1 & 4.6 & 6.9 & 6.9 & 10.4 & 8.4 & 12.7 \\
2 & 4.6 & 6.9 & 7 & 10.4 & 8.6 & 12.6 \\
3 & 4.6 & 6.7 & 7 & 10.2 & 8.7 & 12.5 \\
\hline
\end{tabular}

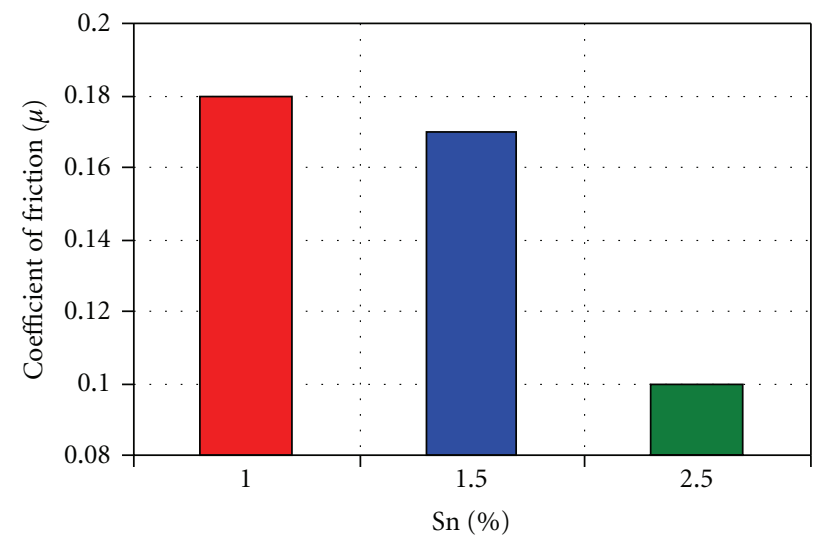

FIGURE 14: The influence of the tin content on the coefficient of friction at a $p \times v$ value of $2.8 \mathrm{MPa} \mathrm{m} / \mathrm{s}$.

having an available energy $E_{0}$ of $100 \mathrm{~J}$ and an impact hammer speed of $5 \mathrm{~m} / \mathrm{s}$.

Table 4 shows the impact energy $(E)$ and toughness strength $(\mathrm{KC})$ values for all alloys sintered at $800^{\circ} \mathrm{C}, 850^{\circ} \mathrm{C}$, and $900^{\circ} \mathrm{C}$ for 50 minutes. The influence of the chemical composition on impact energy is presented in Figure 12, and the influence of the sintering temperature on the impact energy is observed in Figure 13.

The lowest values of the impact energy were observed for samples containing $2.5 \% \mathrm{Sn}$ at all three temperatures, and the higher values were observed for samples with $1 \%$ Sn. Impact energy is about two times as high after sintering at $900^{\circ} \mathrm{C}$ compared to $800^{\circ} \mathrm{C}$, which underlines the effect of microstructural homogeneity, although the change of pore shape and size and more uniform distribution of the pores may also contribute to this behaviour. Higher values of the impact energy may be attributed to the formation of soft phases such as $\mathrm{Pb}-\mathrm{Sn}$ or sulphides of $\mathrm{Cu}-\mathrm{Sn}$ and Fe-Sn in larger quantities, which diffuse into the closed pores, thus, resulting in a microstructure with more plastic regions. Consequently, the higher amount of energy required to fracture a specimen means a tough ductile material.

3.3. Tribological Characteristics. The effect of the tin content on the coefficient of friction for samples sintered $900^{\circ} \mathrm{C}$ for 50 minutes and tested at $p \times v$ value of $2.8 \mathrm{MPa} \mathrm{m} / \mathrm{s}$ is shown in Figure 14 and its values are presented in Table 5.

Specimens containing $1 \% \mathrm{Sn}$ exhibit higher values of the coefficient of friction, and smaller values are observed for the specimens with $2.5 \% \mathrm{Sn}$. This may be possibly due to the presence of some soft phases like $\mathrm{Cu}-\mathrm{Pb}$ and $\mathrm{Fe}$ $\mathrm{Cu}-\mathrm{S}$ which have low share strength in the substrate and 
TABLE 5: Friction coefficient values and linear and gravimetric wear rates of the selected materials.

\begin{tabular}{lcccccccc}
\hline Alloy & $F[\mathrm{~N}]$ & $F_{f}[\mathrm{~N}]$ & $\mu$ & $L_{\text {slide }}[\mathrm{m}]$ & $\Delta h[\mathrm{~mm}]$ & $I_{h} \times 10^{-5}[\mathrm{~mm} / \mathrm{m}]$ & $\Delta V \times 10^{3}\left[\mathrm{~mm}^{3}\right]$ & $I_{g} \times 10^{-2}\left[\mathrm{~mm}^{3} / \mathrm{m}\right]$ \\
\hline 1 & 325 & 58.7 & 0.18 & 1360 & 0.55 & 40.4 & 0.154 & 11.3 \\
2 & 325 & 58.1 & 0.17 & 1360 & 0.34 & 25 & 0.148 & 10.8 \\
3 & 325 & 32.5 & 0.1 & 1360 & 0.24 & 17.6 & 0.135 & 9.8 \\
\hline
\end{tabular}

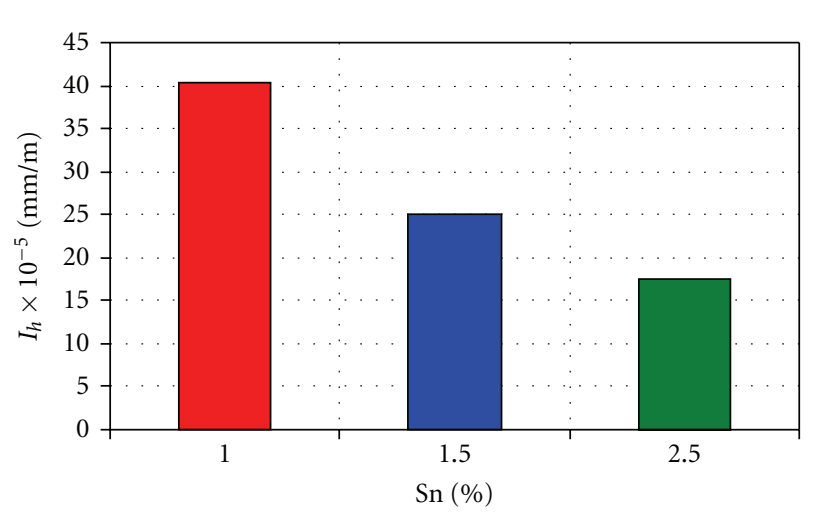

FIGURE 15: The influence of the tin content on the linear wear rate.

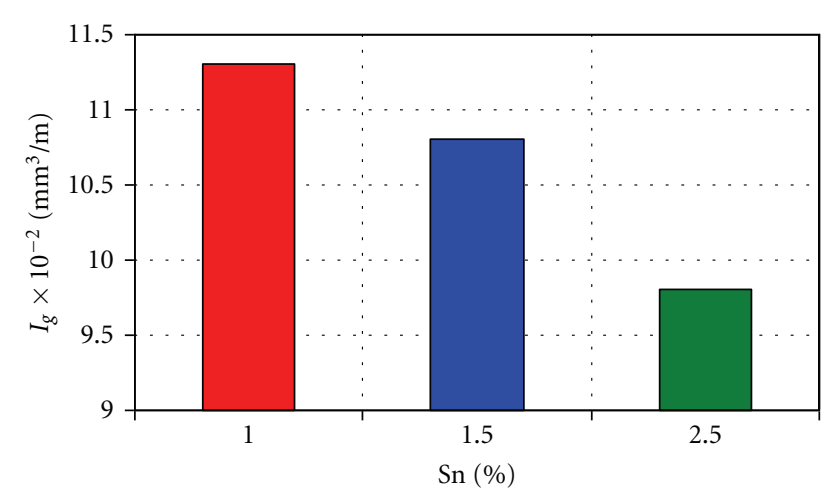

FIGURE 16: The influence of the tin content on the gravimetric wear rate.

are exposed to sliding due to high load [8]. Generally, the variation of the coefficient of friction can be explained on the basis of the hardness variation (Figure 11). The coefficient of friction increases with the decrease of the hardness and the increase of the share strength of the material, which means a direct proportionality with the hardness and an indirect proportionality with the share strength. Besides its great ability to reduce friction between powder particles and between powder particles and die wall during conventional cold die compaction, $\mathrm{MoS}_{2}$ is used to reduce friction between metallic surfaces under certain conditions of application. Another suitable approach for the application of $\mathrm{MoS}_{2}$ is its incorporation in a metallic matrix in order to produce self-lubricating material [9]. Therefore, the presence of the solid lubricant $\mathrm{MoS}_{2}$ contributes to the reduction of the coefficient of friction. The solid lubricant particles get on the containing surface during the sliding process and reduce the friction [10].

The linear wear rate was determined by measuring the final height of the samples at the end of the test and extracting it from the initial height, giving the thickness of the worn layer $(\Delta h)$. Similarly, the gravimetric wear rate was found by weighing the specimens after performing the test and calculating their volume using reference densities. The final results represent the average values of three determinations.

Linear and gravimetric wear rates values are presented in Table 5. Figure 15 shows linear wear rate for samples with different Sn additions sintered in the specified conditions, and Figure 16 shows the gravimetric wear rate as a function of tin content.

From Figures 15 and 16 it can be observed that the wear rates (linear and gravimetric) of the material containing $2.5 \% \mathrm{Sn}$ and tested at $p \times v=2.8 \mathrm{MPa} \mathrm{m} / \mathrm{s}$ exhibited the lowest value of the wear rate. As for friction coefficient, wear rate exhibits an inverse relationship with hardness and a direct relationship with share strength. In spite of the greater amount of lead in samples with $1 \% \mathrm{Sn}$ and $1.5 \% \mathrm{Sn}$, which diffuses to the surface and acts like a solid lubricant, higher mass loss was quantified during the wear test indicating a low wear resistance. This behaviour may be possible due to the higher normal load ( $p=3.2 \mathrm{MPa}$ ) which increases the adhesive component when the substrate is exposed, and the transfer of the soft phases ( $\mathrm{Pb}, \mathrm{Sn}-\mathrm{Pb}$, or sulphides) from the sample surface to the disc is enhanced by increasing the share stress at the surface.

Figure 17 shows representative wear surfaces of the samples sintered at $900^{\circ} \mathrm{C}$ for 50 minutes and tested at $p \times v=$ $2.8 \mathrm{MPa} \mathrm{m} / \mathrm{s}$. Also, the marginal zones of the samples highlighting the material behaviour during wear process can be observed in Figure 18. In order to study the surface damage worn specimens were examined using scanning electron microscopy (SEM).

The worn surfaces present smeared pores and deeper wear tracks indicating that wear occurred due to combined action of adhesive and abrasive mechanisms with transfer and microcutting of the tested material in all compositions.

The worn surface of the material containing 1\% Sn presents deep scars, which are formed along the sliding direction due to the strong adhesion between roughs in contact (Figure 17(a)). The surface layers are modified and the oxide films are damaged by plastic deformation, subsequently new layers being in contact.

Also, during the wear process the rolling or flanging of the marginal zone as well as the exfoliation of the material can be observed (Figure 18(a)). This behaviour is typical to soft and ductile materials and may be explained by the great amount of lead in the material composition.

The wear surface of the sample with $1.5 \%$ Sn shows less deep scars, but the wear surface is rougher and the detached wear particles from the sample surface can be observed (Figure 17(b)). 


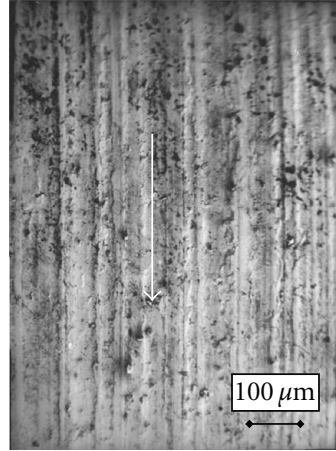

(a)

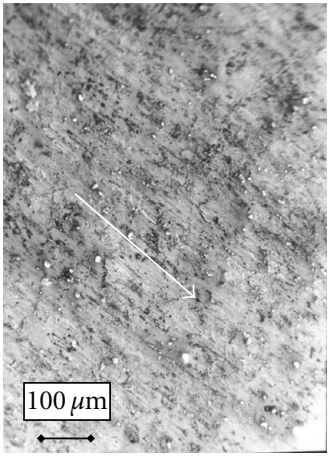

(b)

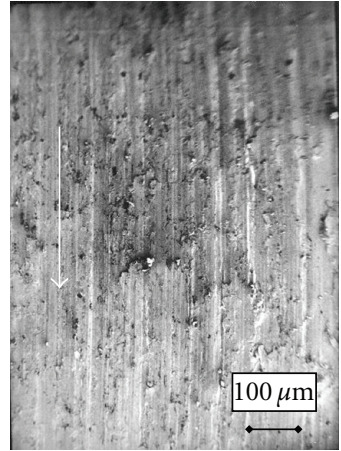

(c)

FIGURE 17: SEM micrographs of the wear scars of the tested materials sintered at $900^{\circ} \mathrm{C}$ for 50 minutes: (a) $1 \%$ Sn; (b) $1.5 \%$ Sn; (c) $2.5 \%$ Sn.

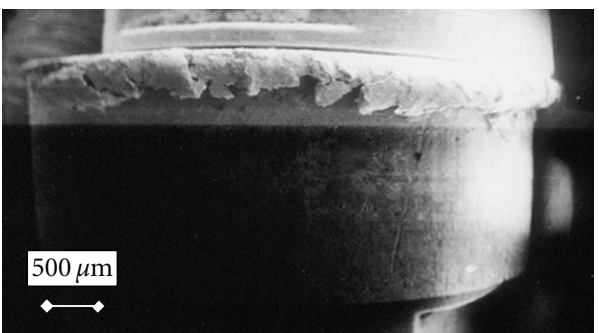

(a)

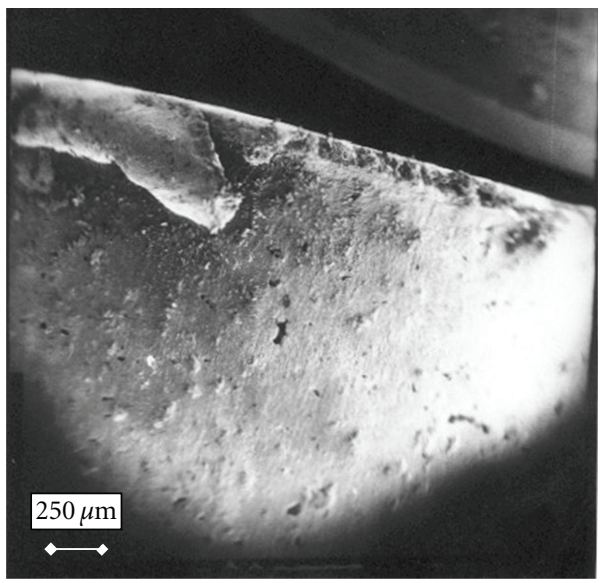

(c)

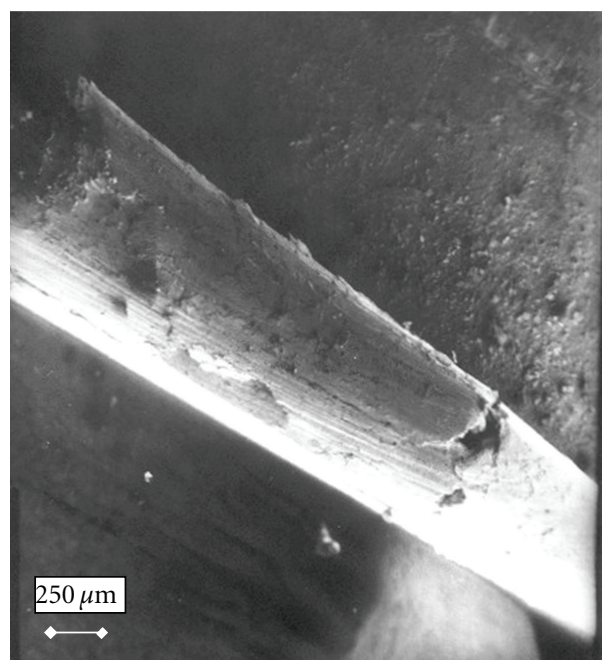

(b)

FIGURE 18: SEM micrographs of the marginal zone of the materials sintered at $900^{\circ} \mathrm{C}$ for 50 minutes: (a) $1 \% \mathrm{Sn}$; (b) $1.5 \% \mathrm{Sn}$; (c) $2.5 \% \mathrm{Sn}$.

Similarly, the rolling and the exfoliation of the marginal material of the sample occurred, but in a smaller rate due to a lesser amount of lead (Figure 18(b)).

The ductile character of the sintered material observed on microscopic scale by "cone-cup" configuration of the interparticle bridges can be also highlighted on macroscopic scale by plastic deformation processes which are slowly developed during the wear process.

The alloy containing $2.5 \% \mathrm{Sn}$ has the higher value of the hardness and the friction coefficient and wear rates have acceptable values. The wear surface of this material is less coarse with finer scars and a smaller number of particles detached from the sample surface due to the failure of the welding bridges between the microcontact zones (Figure 17(c)). A lesser amount of marginal material is rolled and exfoliated (Figure 18(c)).

Surface roughness measurements were carried out on the worn surfaces using a surface profilometer.

Figure 19 shows the 2D surface profile of the samples with compositions 1,2 , and 3 after the wear test. $P_{t}$ is the maximum peak-to-valley height of the $2 \mathrm{D}$ surface profile; $R_{a}$ is the arithmetic mean surface roughness and is the most commonly used parameter to monitor a production process; $R_{z}$ is the surface roughness depth and, as a rule, is used for all types of surfaces; $R_{p}$ is the maximum profile peak height and is useful in predicting bearing characteristics of a surface. 


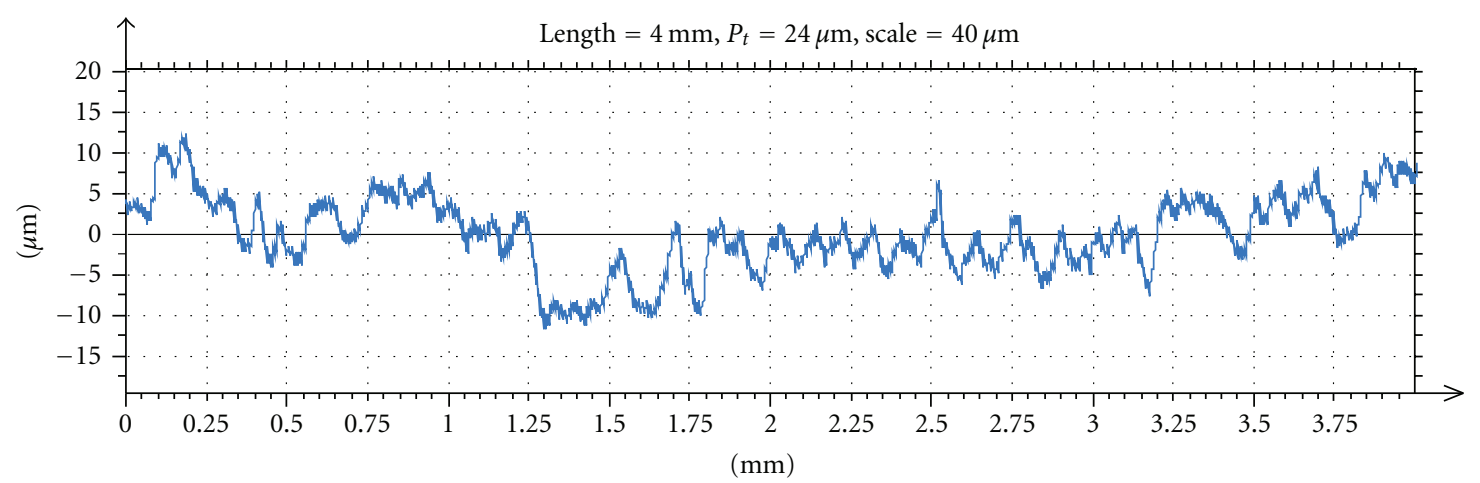

(a) $R_{p}=6.58 \mu \mathrm{m} ; R_{a}=2.09 \mu \mathrm{m} ; R_{z}=12.1 \mu \mathrm{m}$

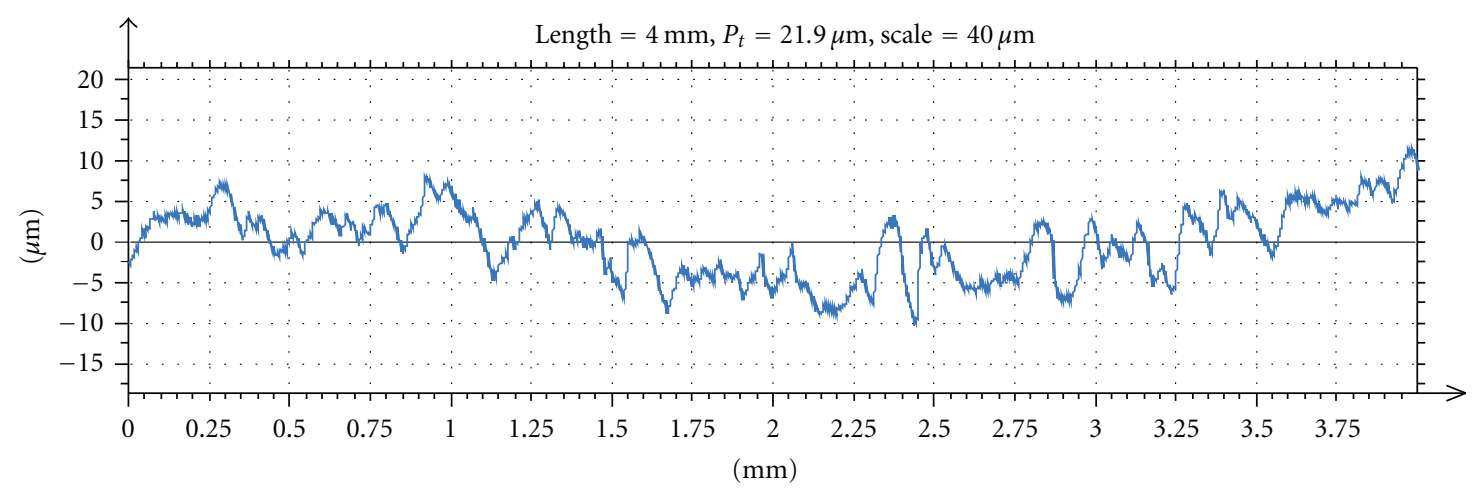

(b) $R_{p}=5.44 \mu \mathrm{m} ; R_{a}=1.89 \mu \mathrm{m} ; R_{z}=11.6 \mu \mathrm{m}$

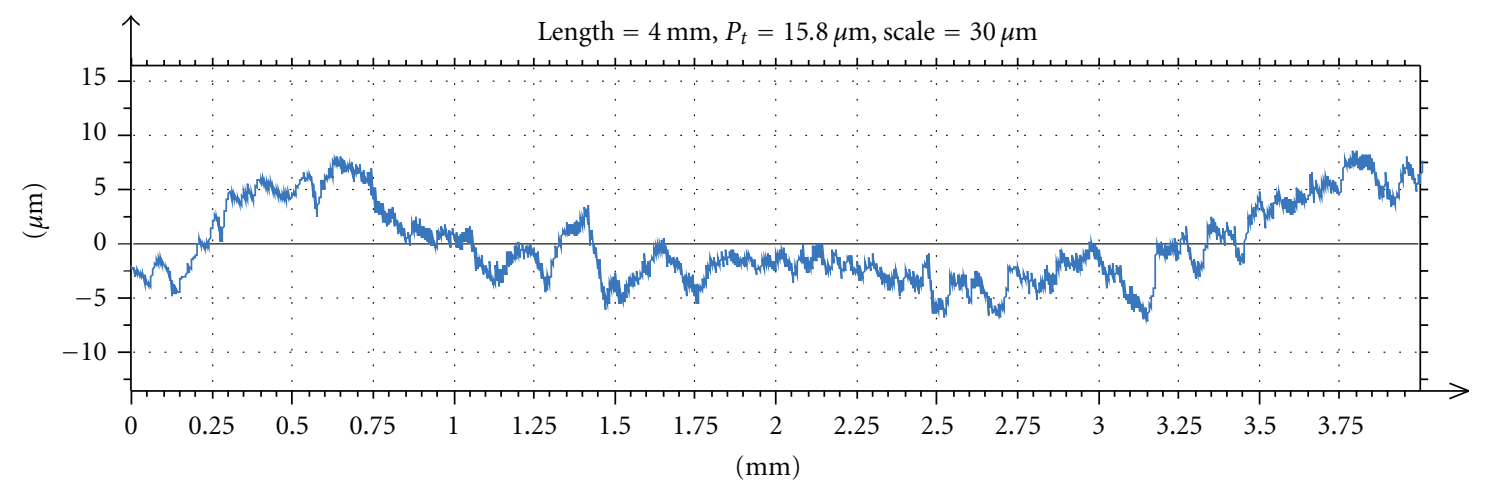

(c) $R_{p}=3.62 \mu \mathrm{m} ; R_{a}=1.09 \mu \mathrm{m} ; R_{z}=7.09 \mu \mathrm{m}$

FIGURE 19: Surface roughness of the sample with $1 \%$ Sn (a), 1.5\% Sn (b), and 2.5\% Sn (c) across the sliding direction.

From the analysis of the surface roughness after the process of wearing it can be observed that the lower values of the roughness parameters are obtained for the samples with $2.5 \% \mathrm{Sn}$, which confirms the results regarding the coefficient of friction and wear rate for this material.

\section{Conclusions}

Considering the physical, mechanical, and tribological behaviour of the selected materials the following conclusions can be drawn.

(i) Alloy no. 3 exhibits optimum properties when sintered at $900^{\circ} \mathrm{C}$ for 50 minutes. (ii) Generally, as the sintering temperature increases the smaller values of the density are obtained due to volumetric dimensional growth during liquid-phase sintering at higher temperatures.

(iii) A relatively homogenous microstructure is achieved when sintering at $900^{\circ} \mathrm{C}$ for 50 minutes with soft and strengthening phases distributed in the ferrite matrix and small pores in larger quantities with a relatively uniform distribution.

(iv) Tensile strength, hardness, and toughness are comparable to those of the existing iron-based materials [11-14]. 
(v) Tensile strength of $205 \mathrm{MPa}$, hardness of $139 \mathrm{VH}_{5}$, and toughness of $12.5 \mathrm{~J} / \mathrm{cm}^{2}$ were obtained for alloys sintered at $900^{\circ} \mathrm{C}$ for 50 minutes and containing $2.5 \%$ Sn due to the presence of strengthening phases which form at higher temperatures and longer sintering times.

(vi) At the $p \times v=2.8 \mathrm{MPa} \mathrm{m} / \mathrm{s}$ the friction coefficient is about 0.1 , the linear wear rate has the lowest value of $17.6 \times 10^{-5} \mathrm{~mm} / \mathrm{m}$, and also the gravimetric wear rate has the lowest value of $9.8 \times 10^{-2} \mathrm{~mm}^{3} / \mathrm{m}$. These results are explained on the basis of the presence of soft phases in the structure, which have low share strength in the substrate and during the high load tests are exposed to sliding. Also, $\mathrm{MoS}_{2}$ solid lubricant additions contribute in the reduction of the coefficient of friction. On the other hand, wear rates exhibit lower values due to increasing the adhesive component at higher normal loads and exposure and transfer of the soft phases from the sample surface to the mating disc. As a consequence, the share stress at the sample surface increases.

(vii) Studying the tribological behaviour of the samples made from the selected materials and tested in dry friction condition (without lubricant) it was observed the dropping off of the friction coefficient as the tin content increases. The linear wear rate and the gravimetric wear rate are smaller as the amount of tin is greater.

(viii) Electronic microscopy analysis of the wear surfaces of the samples sintered at $900^{\circ} \mathrm{C}$ for 50 minutes and tested at $p \times v=2.8 \mathrm{MPa} \mathrm{m} / \mathrm{s}$ shows deep wear tracks indicating that wear occurred due to combined action of adhesive and abrasive mechanisms with transfer and microcutting of the tested material. Also, the marginal regions of the samples with rolled and exfoliated layers highlight the material behaviour during wear process. Deeper scars along the sliding direction due to the strong adhesion between roughs in contact exhibit sample with $1 \%$ Sn and their aspect can be observed on the 2D surface profile. The wear surface of the sample with $2.5 \% \mathrm{Sn}$ is less coarse with finer scars and a smaller number of particles detached from the sample surface. The difference between the scar aspects of the worn surfaces and also the difference between wear depths is emphasized on $2 \mathrm{D}$ surface profiles by pick-to-valley height, $P_{t}$, and roughness parameters, $R_{a}$ and $R_{z}$, which have the lowest values for the sample with $2.5 \% \mathrm{Sn}$.

\section{References}

[1] A. G. Kostornov and O. I. Fushchich, "Sintered antifriction materials," Powder Metallurgy and Metal Ceramics, vol. 46, no. 9-10, pp. 503-512, 2007.

[2] A. G. Kostornov, O. I. Fushchich, and T. M. Chevichelova, "Structurization in sintering of antifriction powder materials based on iron-copper alloys," Powder Metallurgy and Metal Ceramics, vol. 46, no. 11-12, pp. 589-594, 2007.
[3] Verghese and K. Gopinath, "Influence of antimony additions on sintered iron-copper bearing materials," Key Engineering Materials, vol. 29-31, pp. 457-464, 1989.

[4] Y. M. Vasil'ev, G. A. Shvetsova, V. Y. Berent, and N. A. Bushe, "Antifriction properties of an iron-base material containing a manganese ultraphosphate," Powder Metallurgy and Metal Ceramics, vol. 21, no. 7, pp. 592-594, 1982.

[5] L. M. Berger, C. C. Stahr, S. Saaro, S. Thiele, M. Woydt, and N. Kelling, "Dry sliding up to $7.5 \mathrm{~m} / \mathrm{s}$ and $800^{\circ} \mathrm{C}$ of thermally sprayed coatings of the $\mathrm{TiO}_{2}-\mathrm{Cr}_{2} \mathrm{O}_{3}$ system and (Ti,Mo)(C,N)-Ni(Co),"Wear, vol. 267, no. 5-8, pp. 954-964, 2009.

[6] R. M. German, P. Suri, and S. J. Park, "Review: liquid phase sintering," Journal of Materials Science, vol. 44, no. 1, pp. 1-39, 2009.

[7] W.-F. Wang, "Effect of tin addition on the microstructure development and corrosion resistance of sintered 304L stainless steels," Journal of Materials Engineering and Performance, vol. 8, no. 6, pp. 649-652, 1999.

[8] M. Chandrasekaran and P. Singh, "Effect of PB additions on the friction and wear of sintered FE-Cu-SN-MoS 2 ," International Journal of Powder Metallurgy, vol. 32, no. 1, pp. 51-58, 1996.

[9] B. Sustarsic and L. Kosec, "Engineering properties of Fe-MoS powder mixtures," in Proceedings of the Powder Metallurgy World Congress \& Exhibition, pp. 316-321, Granada, Spain, 1998.

[10] S. Dhanasekaran and R. Gnanamoorthy, "Development of self lubricating sintered steels for tribological applications," in Proceedings of the International Symposium of Research Students on Materials Science and Engineering, Chennai, India, 2004, http://mme.iitm.ac.in/isrs/isrs04/cd/content/ Papers/AIS/OR-AIS-1.pdf.

[11] A. Domsa, Tehnologia Fabricarii Pieselor din Pulberi Metalice, Bucuresti, Romania, 1966.

[12] A. Salak, Ferrous Powder Metallurgy, Cambridge International Science, Cambridge, UK, 1995.

[13] K. Tüfekci, C. Kurbanoǧlu, E. Durak, and R. F. Tunay, "Friction and wear properties of $\mathrm{Cu}$ and Fe-based P/M bearing materials," Journal of Mechanical Science and Technology, vol. 20, no. 4, pp. 513-521, 2006.

[14] M. Morakotjinda, R. Krataitong, P. Wila et al., "Sintered FeCu-C materials," Chiang Mai Journal of Science, vol. 35, no. 2, pp. 258-265, 2008. 

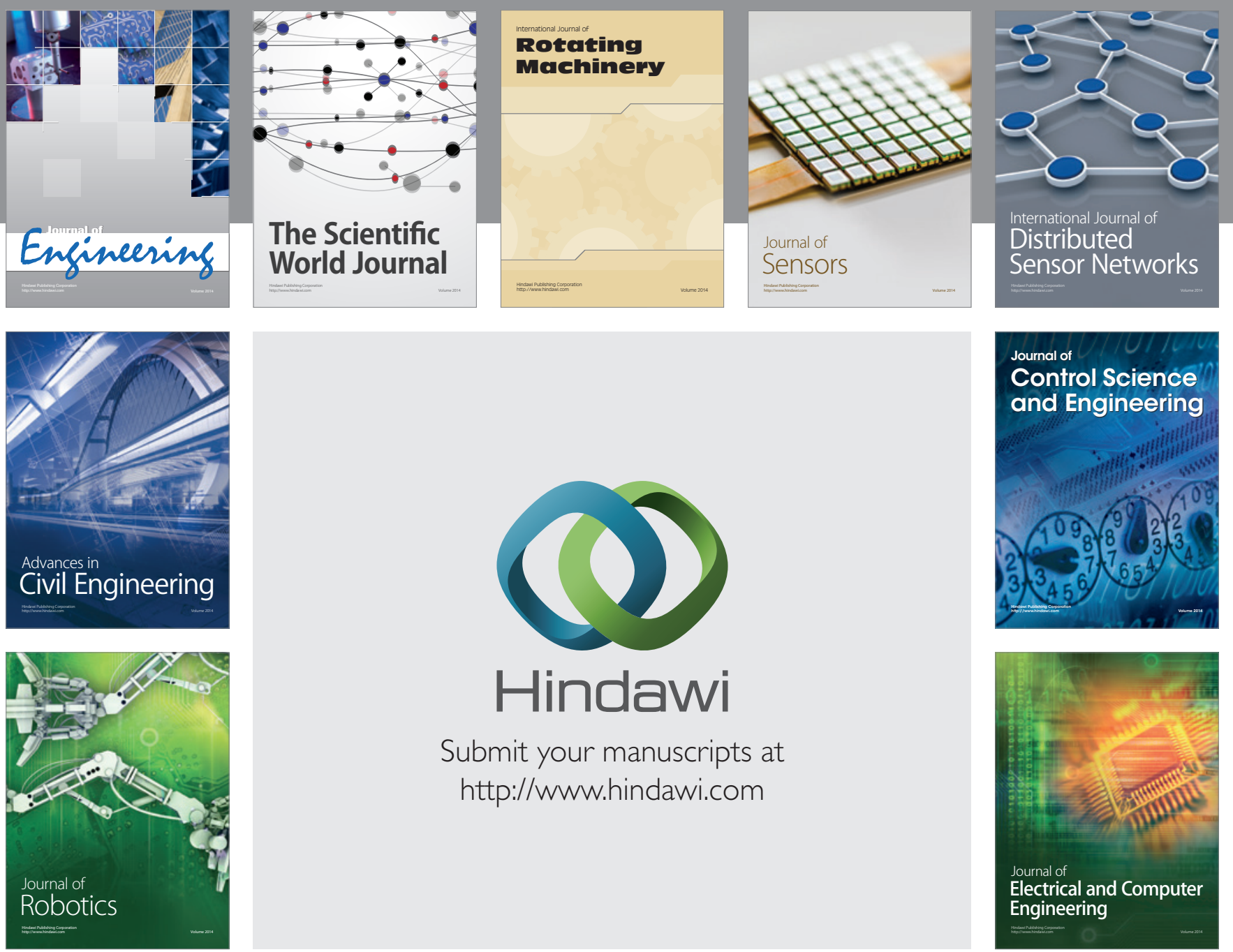

Submit your manuscripts at

http://www.hindawi.com
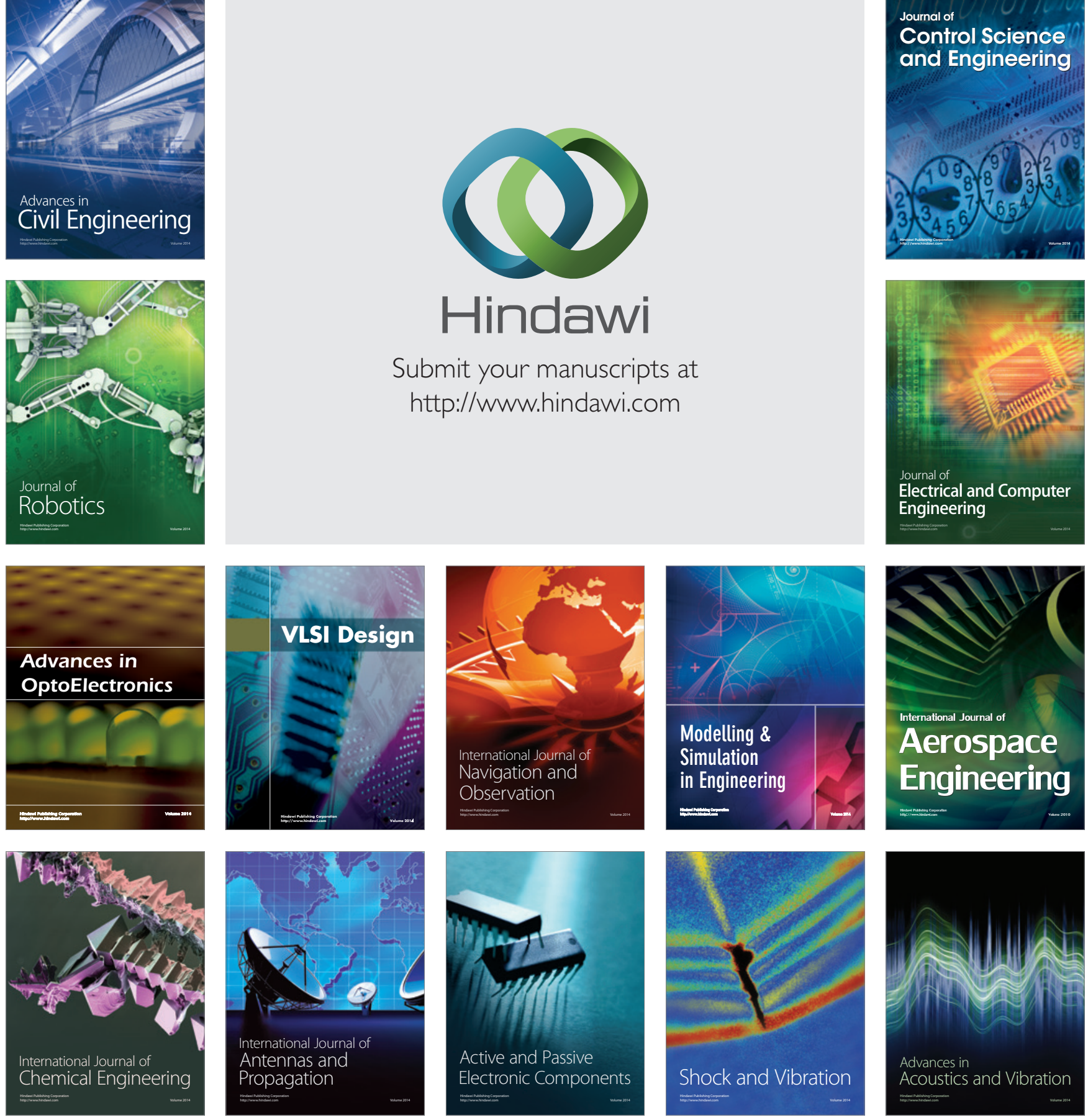